\title{
Flying through hurricane central: impacts of hurricanes on migrants with a focus on monarch butterflies
}

https://doi.org/10.1515/ami-2018-0010

Received July 18, 2018; accepted October 14, 2018

\section{Introduction}

Increased frequency and intensity of extreme weather events, including droughts, heat waves, severe rainfall, and tropical cyclones, are critical outcomes of global climate change [1]. Here, we consider the impact of hurricanes on long-distance, round-trip migrants with a particular focus on monarch butterflies (Danaus plexippus). Tropical cyclones (hereafter, hurricanes, as they are known when they form in the Atlantic Ocean) are relatively more predictable than other extreme events if only because they are restricted to specific coastal regions and exhibit regular seasonality (Fig. 1). Not surprisingly, e focus is often on the intense damage that hurricanes cause directly [2], including destruction of local habitat through both extreme wind and rainfall (which can inundate resources). Both have the potential to transform landscapes, at least temporarily; although research suggests that hurricanes naturally shape ecosystems to be adaptive and thus resilient to repeat disturbances [3-4]. Less is known about the impacts on faunal communities, yet research on resident communities within hurricane zones suggest they too are resilient to these regular disturbances. For instance, local (non-migratory) bird communities shift composition in response to changes in forest canopy but generally revert to pre-hurricane composition within a few years [5-7] (but see [8] for a study where a similar recovery did not occur for resident bats).

The zone of impact and timing of the Atlantic hurricane season (Fig. 1) coincide with the fall migration for birds, bats, and insects (Fig. 2). Hurricane impacts on migrants may be fundamentally different from those of resident species [9]. Importantly, migrating species are known to be particularly sensitive to climate and weather patterns since they integrate changes in multiple regions which can carry over from season to season [10-11]. Migratory phases are especially risky periods, and many species have the highest mortality rates during this period of their annual cycle [10]. Thus, migratory species may be particularly 


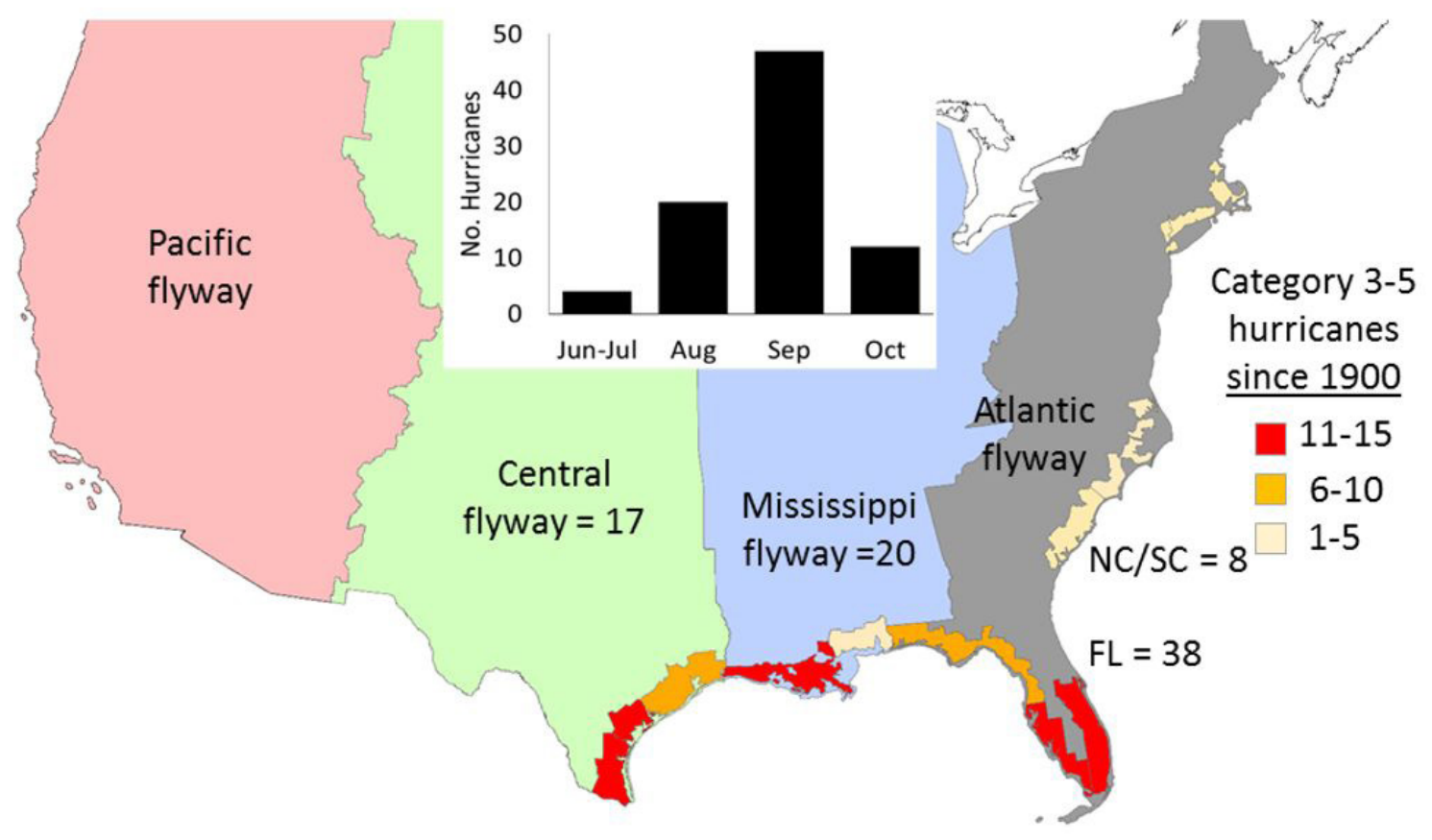

Figure 1. North America has been separated into four primary flyways based on migratory bird flight paths. Strong Atlantic hurricanes (Categories 3-5) are most common in September (inset), a peak of migration season for many species (See Fig. 2). Atlantic hurricanes are concentrated along the gulf coast and the Southeastern coast of Florida (b). Hurricane data from the National Hurricane Center. Flyways shapefile obtained from United States Geological Survey website (downloaded January 2018).

prone to declines as a result of increasing threats from storms [12]. Another challenge for understanding the ecological impacts of hurricanes on migrants is that fall migration, when hurricanes occur, is generally less wellstudied compared to spring migration [13]. As hurricanes increase in both frequency and intensity with the rise of global warming [14], understanding the various ecological impacts of hurricanes on both resident and migratory species should be a focus of global change research.

Impacts to individuals along a migratory route can either be direct (when individuals encounter active storms) or indirect (where storms impact habitat structure, resource distribution or interacting species along migratory flyways). While the direct impacts of hurricanes are likely to be negative (e.g., halting migratory progress, injuring or killing individuals or blowing them off-course), the outcome of indirect effects on resource distribution is less clear. This is because ecological changes in habitat, resources, or community structures can have variable effects depending on the ecological needs and specific interactions of each species [9].

Texas is a critical corridor for many species that migrate between North America and Central/South America (Fig. 1). For many of these species, the timing of fall migration specifically through Texas (Fig. 2) coincides with peak hurricane season in the Atlantic (Fig. 1, inset). Texas also

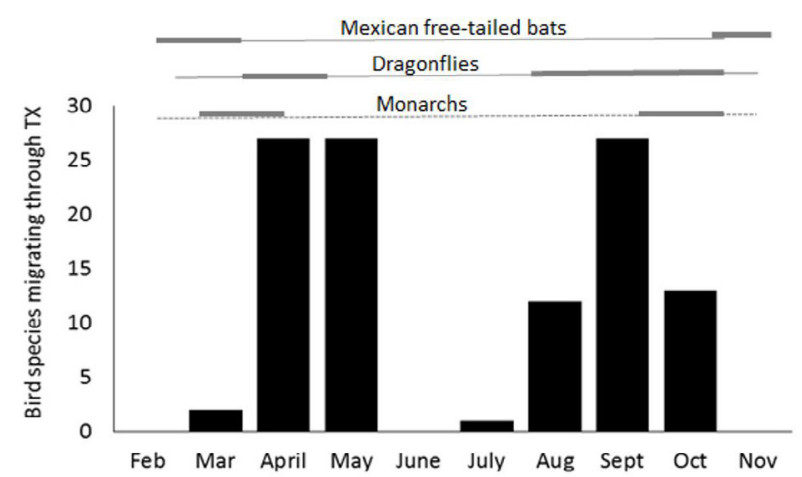

Figure 2. Migratory timing for different species groups in Texas. The number of non-resident bird-species that show peak migration during each month are shown by the black bars (data from e-bird, see Appendix 1). Peak migration timings (thick lines) are also shown for monarchs, migratory dragonflies, and Mexican free-tailed bats. Migratory dragonflies and Mexican free-tailed bats are also resident in Texas (as shown by the thin solid lines). Although a small population of monarchs resides in Texas throughout the summer (indicated by the dotted line), the vast majority breed much further north.

has the driest climate compared to other states that are impacted by hurricanes (e.g., Louisiana, Mississippi, Alabama, Florida, the Carolinas) and so the availability of biotic resources there may be disproportionately affected by increased rainfall. Hurricanes that make landfall in Texas are fairly common (Fig. 1, Fig. 3); as such, any lag effects of hurricanes are likely to overlap, especially for 


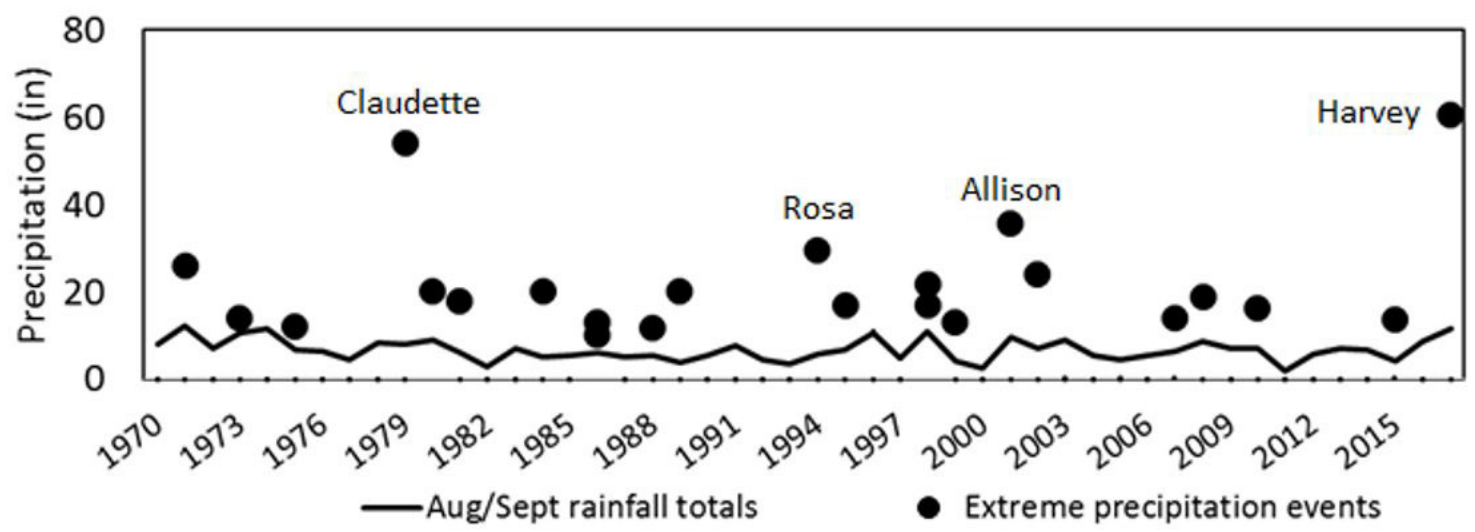

Figure 3. Texas rainfall during August-September (black line, averaged across weather stations, values from noaa.gov/cag, retrieved October 2017) compared to local records of highest rainfall during extreme precipitation events (here, defined as local rainfall above $>10 ")$ associated with hurricanes (black circles, data from National Hurricane Center).

effects where recovery times are long (e.g., forest damage). Thus, it may be particularly challenging to tease apart the long-term effects of multiple, overlapping hurricanes on regional ecosystems.

One of the most severe hurricanes to hit Texas was Hurricane Harvey, which made landfall near Houston, Texas in late August 2017. Harvey was the largest rainfall event recorded in the United States [15]. Harvey-related rainfall covered a substantial portion of eastern Texas, with the highest rainfall totals near Houston (Fig. 4a). Harvey caused extensive flooding (Fig. 4b), much of which continued for several weeks after Harvey dissipated [15]. The impacts of Harvey on primary productivity were profound, with a substantial increase of green vegetation evident in the period immediately after (Fig. 4c,d), even though this would normally be a time of vegetative senescence.

Most of the research on the effects of hurricanes has focused on birds; we review that literature and also present basic information about other groups that exhibit regular, round-trip migrations and are thus also likely to be impacted by hurricanes. We then present a case study focused on the eastern migratory monarch butterfly to evaluate the potential hurricane impacts along their migratory route. Monarchs famously migrate south through Texas in the fall to overwinter in a restricted set of mountains in central Mexico. The following spring, monarchs fly north where they stop in the Texas region to produce a single generation, which then continues the migration north to their summer breeding grounds [16]. Thus, individuals may be affected either directly by hurricanes as they fly through Texas in the fall, or indirectly (in either fall or spring) by alterations to resource distributions within their migratory corridor.

\section{The impacts of hurricanes on migratory birds}

Most research on the effects of hurricanes on migration has focused on birds. Species using the Central, Mississippi, and Atlantic flyways are most likely to be impacted by hurricanes (Fig. 1). Cyclones (the hurricane equivalent in the Pacific) are much less likely to make landfall since they move from east to west and thus impacts to species using the Pacific flyway are much rarer. Of course, the most direct type of impact is that a hurricane can physically alter the flight path and/or injure or kill individuals. Individuals may be blown off-course during hurricanes, sometimes spectacularly out-of-range (see [17] for many examples) and, interestingly, the eye of a hurricane has been known to trap thousands of individuals and move them slowly along within the interior of a hurricane [18]. Despite this, as a group, migratory species are generally resilient to the impacts of hurricanes; they appear to be able to modify their routes to avoid affected areas during storms and return relatively quickly after storms have passed [17]. For instance, after Hurricane Rita in 2005, departures of migratory birds from the impacted area declined sharply, but migrants appeared to shift their location to stopover habitat further north [19]. This is in contrast to resident birds in the same region which showed a sustained decline immediately following the hurricane and throughout the subsequent winter, with no obvious increases elsewhere [19]. These results suggest that migratory birds may shift their distributions more in response to active storms relative to residents, which is perhaps not surprising. A similar phenomenon was documented with Hurricane Katrina, which made landfall 
(a) Rainfall during Harvey

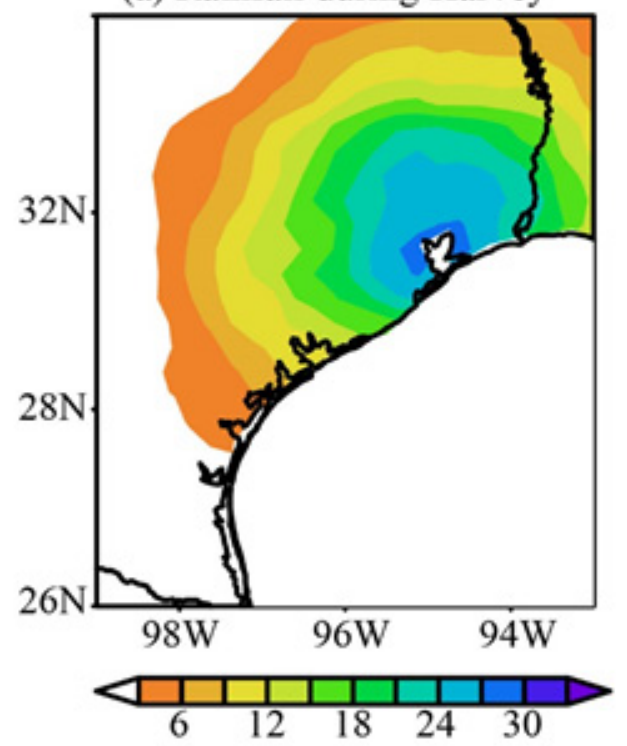

(c) Greenness before Harvey

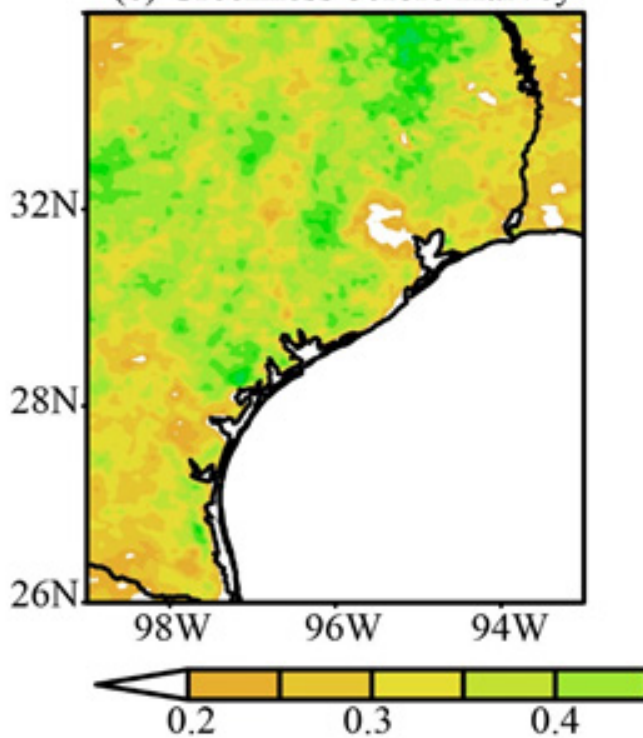

(b) Flood areas after Harvey

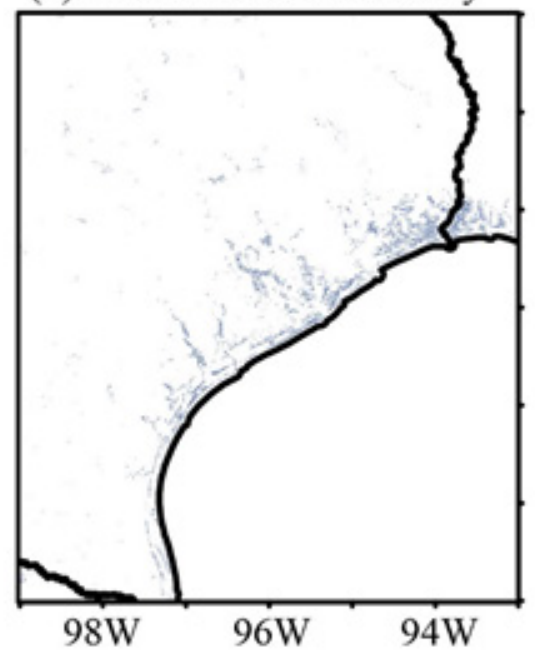

(d) Greenness after Harvey

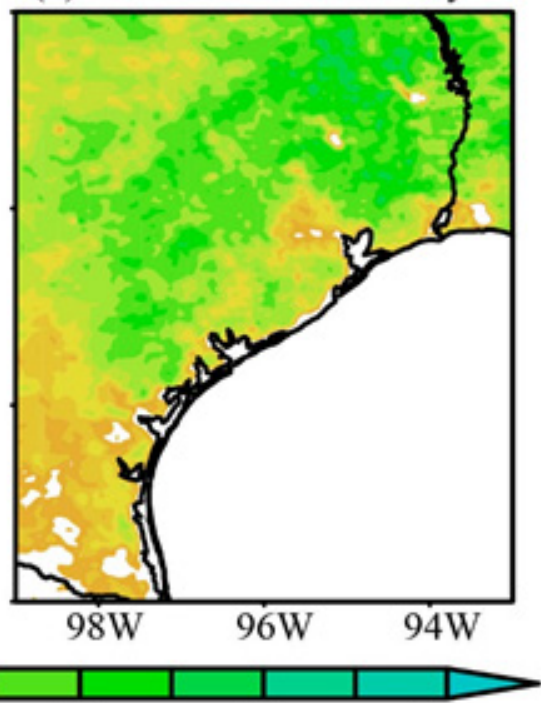

Figure 4. (a) Satellite observed rainfall total (in) from August 23 - September 3, 2017 [45] during Hurricane Harvey was the highest recorded anywhere in the United States (data from Tropical Rainfall Measurement Mission). (b) Harvey was associated with extensive flooding from August 31 - September 2, 2017 as observed from the Moderate Resolution Imaging Spectroradiometer satellite [46]. Increased rainfall had a large impact on primary productivity, which normally decreases in the fall, but instead increased: greenness index (c) pre-Harvey from August 8 - 22, 2017 and (d) post-Harvey from September 4 - 18, 2017. Patterns of greenness derived from National Oceanic and Atmospheric Administration- Normalized Difference Vegetation Index [47] based on AVHRR satellite imagery.

that same year near the Pearl River Delta in Mississippi, also important stopover habitat for migrating birds. Again, the number of migrants in the region declined sharply, but immediately increased in surrounding, less-disturbed woodlands [20]. However, migrants began returning to the delta as soon as vegetation resprouted even though the river bottom was badly damaged [20]. It is important to note that migratory birds are not always immune to the direct physical impacts of severe storms. For instance, an April storm that spawned a tornado in coastal Louisiana in 1993 killed upwards of 40,000 birds, most of them migratory [21]. Although not a hurricane, the example is instructive. The difference in lethality may have been due to a more sudden appearance of a storm with greater wind 
speeds, but also could be due to birds approaching the storm from over the Gulf of Mexico rather than over land, thus providing no immediate refuge [21].

In contrast, indirect impacts of hurricanes have the potential for more significant effects on migratory birds than direct impacts [18]. Hurricanes change tree canopy structures, immediately impacting bird habitat, which could be positive or negative depending on the successional associations of each species. Changes in food resources, critical for maintaining energy through migration, can also substantially affect survival. Hurricanes have been shown to decrease some local insect populations [9,19,21], but birds can also shift their diets to more abundant insect species [17], in addition to shifting their location. Changes to the distribution of fruits and flowers can be both immediate and long lasting post hurricane destruction, which can impact the availability of these resources along migration corridors [17]. However, most neotropical migrant birds are insectivorous so the extent to which fruit and nectar loss affects migratory birds is not clear and should be examined species by species.

\section{Other long-distance migrants in North America}

The other major groups of long-distance, round-trip migratory species in North America are certain species of insects and bats, neither of which has been well-studied in terms of the impacts of hurricanes. Several North American Lepidoptera species are known to complete round-trip migrations [23]. The most well-known is the monarch butterfly (D. plexippus), but also included are the painted lady butterfly (Vanessa cardui) and several moths. These include black witches (Ascalapha odorata) and others that are crop pests [23] including some armyworm moths (Mythimna sp. and Spodoptera sp.) and cutworm moths (Agrotis sp.). There are also five species of migratory dragonflies (Anax junius, Tramae lacerata, Sympetrum corruptum, Pantala flavescens, and P. hymenea), which have both solely residential and solely migratory populations throughout their ranges [24]. Although little is known about their migration, the migratory timing of these species through Texas also coincides with peak hurricane season (Fig. 2) so there is potential for both direct and indirect effects.

There are several migratory bats in North America, but only some migrate through hurricane-prone zones, including the hoary bat (Lasiurus cinereus), the southern yellow bat (L. ega), several myotis (Myotis auriculus, $M$. gisescens, M. yumanensis), and the Mexican long-tongued bat (Choeronycteris mexicanus) [25]. The best-studied and most abundant migratory bat is the Mexican free-tailed bat (Tadarida brasiliensis). This species migrates through Texas much earlier in the spring and much later in the fall than other migrants (Fig. 2) and thus is much more likely to avoid direct impacts of hurricanes (Fig. 1b), but some also live year-round in Texas [26].

There is very little research on this topic for bats and insects. One report suggested that a high pressure system occurring after the passage of Hurricane Floyd in New Jersey triggered a mass migration of monarchs and three species of migratory dragonflies [27] although neither positive nor negative impacts of this sudden swarm were noted. Monarchs that arrived in Australia (around 1871) may have been blown from islands in the western Pacific by cyclonic winds [28]. Interestingly, a swarm of several hundred black witch moths (Ascalapha odorata) were observed coming ashore within the eye of hurricane Claudette in 2003 and many survived by finding refuge in buildings and trees when the hurricane passed through (29).

Mexican free-tailed bats roost mostly in caves or beneath bridges, so this species' habitat is less likely to be impacted by storm damage. But other species of migratory bats roost in trees or under bark, so storm damage could have a negative impact on their habitats. Note that most of the migratory insect and bat species cited here have both residential and migratory populations throughout their range, so it is more difficult to parse out the effects of hurricanes on migration per se rather than on other phases of the annual cycle. More research of the potential impacts of hurricanes on migratory species other than birds is needed for a holistic understanding of how changing weather conditions and extreme events influence ecological communities.

\section{The monarch butterfly as a model system to understand the impact of hurricanes}

The eastern population of the monarch butterfly has four distinct migratory phases (illustrated in Fig. 5). Two phases, overwintering and summer breeding, take place well outside the migratory flyway that intersects with the main Atlantic hurricane zone. However, unlike birds and bats in which a single individual completes the migratory route, monarchs (and most other migratory insects) complete their migration over multiple generations. During spring migration, the population stops in the 


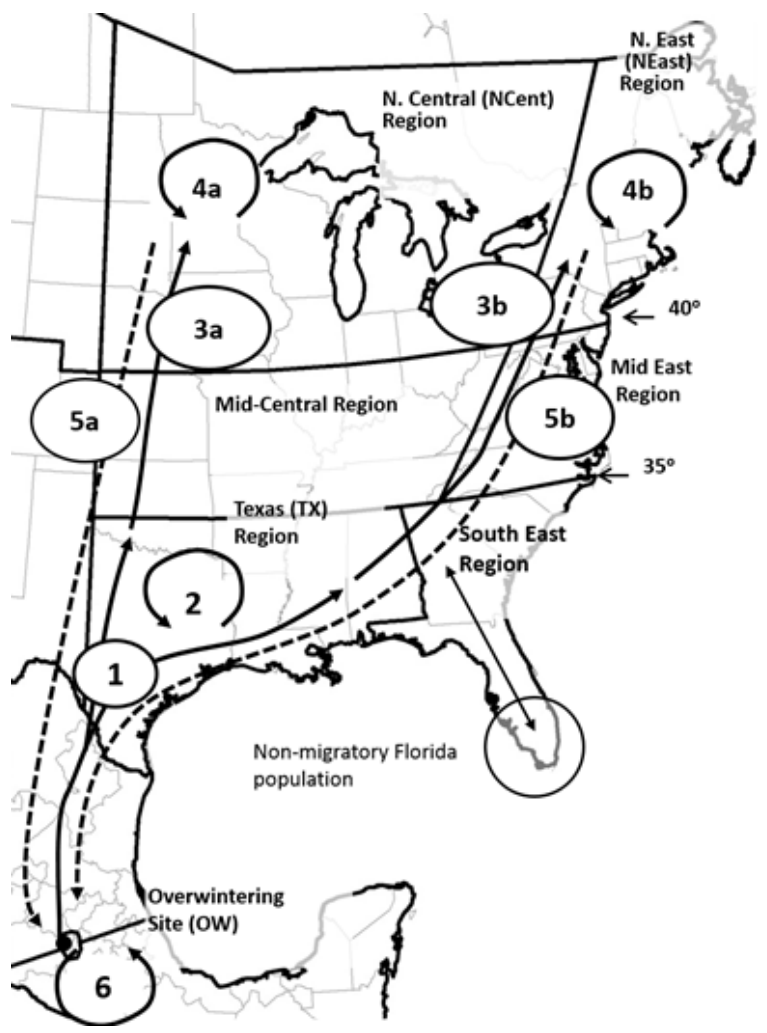

Figure 5. Range map of the eastern migratory population of monarchs illustrating major steps in their annual cycle. Arrows and numbers represent transitions from one stage of the cycle to the next, which often involve movement from one region to another. Steps include: (1) Spring migration from overwintering sites in Mexico. (2) Reproduction by the migratory generation to produce first new generation of the year in the southern United States (Texas region). (3) Migration to the North-central (3a) and Northeast (3b) regions. (4) Reproduction and population build-up in the Northcentral (4a) and Northeast (4b) regions. (5) Fall migration from the North-central (5a) and Northeast (5b) regions. (6) Overwintering in Mexico from late fall through early the following spring. Reprinted with permission from [48].

Texas region and produces a single brood that continues further north for summer breeding, where an additional 2-3 generations are produced. In the fall, the final generation of the summer season heads south, where they primarily migrate through Texas without reproduction (but see below). Another factor that makes monarchs a particularly good study species is that they are one of the most intensively monitored species in the world, with a network of over 20 citizen science programs across North America that collect data every year on almost every aspect of their ecology [30]. Finally, although not a focus of this review, there is also a non-migratory population of monarchs in Florida [16], the state that experiences the highest incidence of Atlantic hurricane strikes (Fig. 1). This presents a unique opportunity to compare the impacts of hurricanes on migratory (in Texas) and non-migratory (in Florida) populations of a single species. For these reasons, the monarch butterfly thus offers an excellent model system to study the impacts of hurricanes. Here, we explore the potential impacts of hurricanes in Texas on migratory monarchs in order to establish a framework for study and also anticipate how increased storm intensity and frequency could impact monarchs in the future. We use this example to develop specific recommendations for expanding research of how hurricanes impact migratory species in general.

As is true for birds, the most immediate impact of hurricanes on monarchs is direct mortality from being caught in a storm or individuals being blown off-course by high winds. While there are accounts of triggered monarch movement [27] or monarchs being carried far out of range [28], there is no evidence of mass mortality to date and anecdotal accounts suggest they may be able to "hunker down" during severe storms and avoid being injured or killed [32]. Most monarchs pass through the hurricane zones in October (Texas) and November (Mexico, also subject to hurricane activity), avoiding the majority of major hurricanes which occur in September or earlier (Fig. 1). Thus, based on the current hurricane seasonal timing, monarchs and hurricanes are generally unlikely to directly cross paths. This means, for now, indirect impacts of hurricanes on resource distribution is likely to be much more important. However, as the length of a typical Atlantic hurricane season may be getting longer [31], there is a growing possibility of hurricanes directly impacting migrants. Interestingly, it may be the potential for an expanding hurricane season into spring that could be of greater concern in terms of direct mortality. Hurricane season officially starts in May, although there are currently no records of strong hurricanes making landfall in Texas before June, but this could change in the future as hurricane seasons get longer. During spring migration, monarchs stop to lay eggs in Texas so an unusually early hurricane could devastate developing caterpillars that have no means of escape. Recent research suggests that spring recruitment is a major factor influencing annual population sizes [33,34], so an expanding hurricane season into spring has the potential to negatively impact monarch population growth.

For migrating birds, studies of the indirect effects of hurricanes have focused on damage to trees. However, this may be less of an issue for monarchs since they are generally associated with open habitats outside of winter [33]. While migrating monarchs do roost in trees in the fall, it seems likely that they could avoid areas of the highest damage and find nearby trees for roosting, although this has not been studied directly. A potentially more 
important indirect impact of hurricanes is increased fall primary productivity, especially of herbaceous vegetation which was substantial after Hurricane Harvey (compare Fig. 4c,d). This flush of new vegetation could have either positive or negative impacts on monarchs. In the fall, monarchs are limited by the amount of nectar available to bolster their lipid reserves for winter [35] and recent studies have shown that increased nectar availability in the fall may lead to higher migratory success [36]. Indeed, increased nectar availability in the fall could positively impact many migrating species, including butterflies, bats and nectarivorous birds.

On the other hand, out-of-season resource availability may disrupt migration by attracting individuals to stay in areas and slowing or even preventing arrival at their ultimate destination [37]. For monarchs, hurricanes may drive the appearance of out-of-season milkweeds whose new growth may be triggered by increased rainfall. Fall milkweeds are associated with individuals halting migration and breaking reproductive diapause [38]. To date, this phenomenon is most associated with exotic, tropical milkweed (Asclepias curassavica), which tends to be both more common (Fig. 6a) and in better condition (more nutritious) later in the year because it is newer growth [39]. Egg-laying is more common where exotic milkweeds dominate in the fall (Fig. 6b) and thus these patches (most often people's gardens) can support a winter-breeding population [38]. The general fate of these late-breeding individuals is currently the topic of controversy and it is unknown if they contribute to the next generation or are reproductive dead ends [39-43]. Further, their breeding is often associated with increased disease load [37,38].

While gardens with tropical A. curassavica are relatively limited across the Texas landscape, flushes of native milkweed caused by extreme rainfall have the potential to vastly increase out-of-season milkweed availability relative to A. curassavica planted in people's gardens. This is evident by the substantial flush of vegetation seen post-Harvey (Fig. 4c,d). Milkweeds in general respond well to disturbance by resprouting. For instance, summer burning and mowing [40,41] have caused local flushes of native milkweeds. Anecdotal reports after Harvey indicated unusual growth of native

\section{a) proportion of milkweed counted}
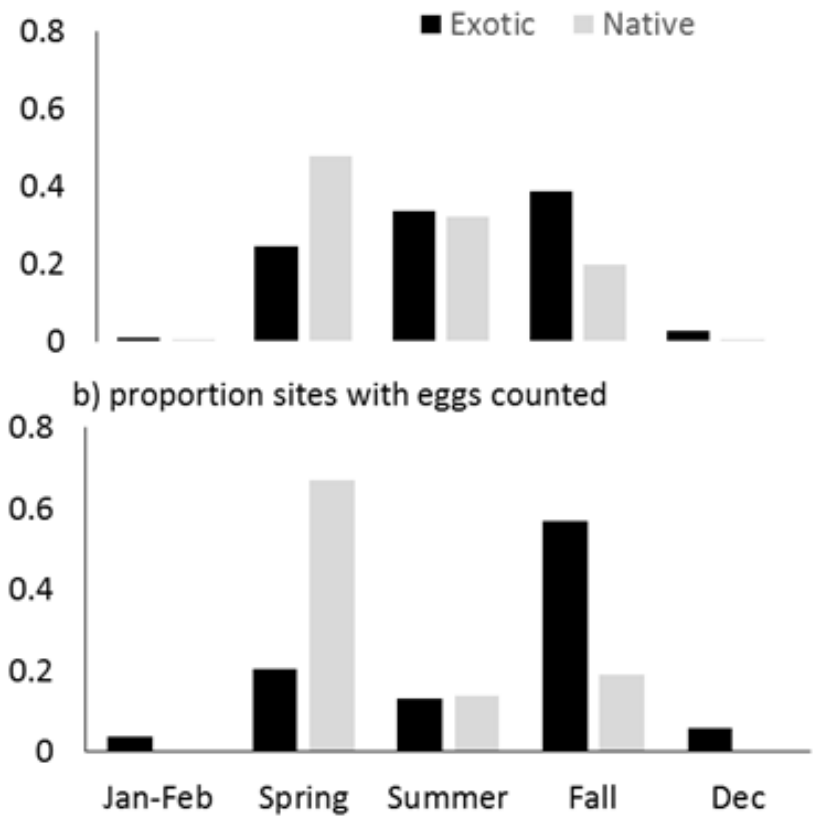

Figure 6. Nationwide surveys show that monarchs preferentially lay eggs in the spring, unless sites are dominated by exotic milkweed [39]. Here, we show this pattern for Texas data only indicating exotic milkweed is more common in the fall (a) and also that egglaying increases in the fall only in sites dominated by exotic species (b). Data retrieved from mlmp.org (September 2017).

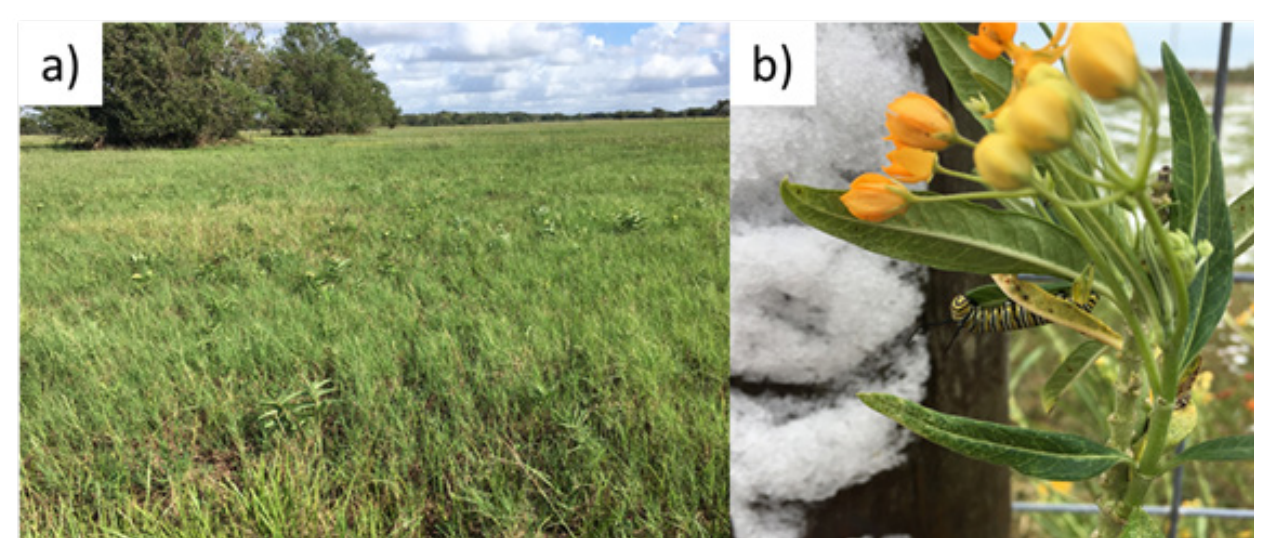

Figure 7. Native milkweed (Asclepias viridis) and exotic milkweed (A. curassavica) present in the region post-Harvey (a). A. viridis seemed more common and less senesced in mid-October in areas that flooded after Harvey (D. Berman, personal observation). (b) A monarch caterpillar feeding late in the season (12/6/2017) following snow on $A$. curassavica in an area that had been inundated by Harvey-induced flooding. Photos by D. Berman. 
milkweed throughout the landscape (Fig. 7a), with reports of caterpillars feeding, even after a December snow (Fig. 7b). The controversy over the impact of exotic milkweed planted in gardens suggests that a greater out-of-season flush of milkweed caused by hurricane-associated rainfall should also be the focus of future studies since they too could have a negative impact on migrating monarchs.

Finally, changes to regional ecosystems, both through storm damage, increased rainfall and zones of long-term inundation may have long-lasting impacts on resource distribution and this has also received very little attention. Hurricanes and their associated rainfall are coming with greater frequency and intensity and any lag effects may therefore be increasingly difficult to tease apart. For instance, monarchs are likely limited by the distribution of resources in the spring [33,34]. It is unknown if increased precipitation during fall hurricanes could lead to more or possibly less growth the following spring. Yet this could be an important contributor to reproductive success the following year or even beyond. It is critical that any examination of the indirect impacts of hurricanes on the distribution of ecosystem resources consider both short and long-term effects on resources.

\section{Conclusions}

Research suggests that migrants generally avoid the most negative impacts of Atlantic hurricanes, and so future research should focus on indirect impacts; specifically how hurricanes impact resource distribution. Most research to date has been on birds, but bats and insects also constitute a substantial portion of migrants each year. Insects in particular are likely to be influenced by the distribution of resources in their migratory pathway because most have multi-generational migrations (in contrast to vertebrate migrants) and thus are often breeding along their migratory routes. Based on this review of the bird literature and an exploration of other groups likely to be impacted, we suggest the following priorities for future research on how hurricanes may impact migrating species: First and most obviously, we should broaden taxonomic focus to include bats and insects. We should continue to evaluate the extent to which migrants may avoid the most damaging direct effects of hurricanes. One way to explore that may be to leverage the use of weather radar which is increasingly being used to track individuals responding directly to storms [18]. Second, we should focus our research on both the immediate and potential longer-term impacts of hurricanes on vegetation distribution. Specifically, we need to determine how increased frequency and intensity of storms might impact resource distribution. Third we should determine if there are commonalities between migrants and residents in their responses to hurricanes. One pathway to this would be to explore how Atlantic hurricanes in Texas impact migrating monarchs vs. Florida hurricanes that impact sedentary monarchs. Finally, considering that hurricanes were traditionally relatively infrequent events in any one location, it is important to understand how well migrating species can adapt to hurricanes, especially as they increase in frequency and intensity. Is there anything about their current behavior when encountering hurricanes (beyond shifting direction) that is an adaptation to buffer them from hurricane damage? How migrating species are able to respond to intensifying hurricanes may serve as a barometer for how species continue to be impacted by global change. Monarchs, with their unique life history and a network of observers tracking their biology every year may serve as an ideal model system to explore these important questions.

Acknowledgements: We thank Andy Davis for inviting us to contribute to this special issue and the helpful suggestions of an anonymous reviewer. We thank all the program directors and volunteers of citizen science monitoring projects that open up avenues of research that have traditionally been out of reach. In particular, we thank the Monarch Larva Monitoring Project volunteers in Texas who collected data that was used in this review. Field observations and insight were provided by David Berman, Jeff Pippen and Andra Doherty. Funding for writing this paper was provided by NSF (EF-1818934, EF-1702179, EF-1818898, EF-1818802 and EF-1702635).

\section{References}

[1] Coumou, D., Rahmstorf, S., A decade of weather extremes. Nature climate change, 2012 2, 491

[2] Everham, E.M., Brokaw, N.V., Forest damage and recovery from catastrophic wind. The botanical review, 1996, 62, 113-185

[3] Lugo, A.E., Rogers, C.S., Nixon, S.W., Hurricanes, coral reefs and rainforests: resistance, ruin and recovery in the Caribbean, AMBIO: A Journal of the Human Environment, 2000, 29, 106-114

[4] Lugo, A.E., Visible and invisible effects of hurricanes on forest ecosystems: an international review. Austral Ecology, 2008, 33, 368-398

[5] Tejeda-Cruz, C., Sutherland, W.J. Cloud Forest Bird Responses to Unusually Severe Storm Damage, Biotropica: The Journal of Biology and Conservation, 2005, 37, 88-95

[6] Rittenhouse, C. D., Pidgeon, A. M., Albright, T. P., Culbert, P. D., Clayton, M. K., Flather, C. et al., Avifauna response to hurricanes: regional changes in community similarity, Global Change Biology, 2010, 16, 905-917 
[7] Perdomo-Velázquez, H., Andresen, E., Vega, E., Schondube, J. E., \& Cuarón, A. D. (2017). Effects of Hurricanes on the Understory Forest Birds of Cozumel Island. Tropical Conservation Science, 10, DOI: 10.1177/1940082917737759

[8] Pedersen, S. C., Genoways, H. H., \& Freeman, P. W. (1996). Notes on bats from Montserrat (Lesser Antilles) with comments concerning the effects of Hurricane Hugo. Caribbean Journal of Science, 1996, 32, 206-213

[9] Dobbs, R.C., Barrow, W.C., Jeske, C.W., DiMiceli, J., Michot, T.C., Beck, J.W., Short-term effects of hurricane disturbance on food availability for migrant songbirds during autumn stopover. Wetlands, 2009, 29, 123-134

[10] Faaborg, J., Holmes, R.T., Anders, A.D., Bildstein, K.L., Dugger, K.M., Gauthreaux, S.A., et al., Recent advances in understanding migration systems of New World land birds. Ecological monographs, 2010, 80, 3-48

[11] O‘Connor, C.M., Norris, D.R., Crossin, G.T., Cooke, S.J., Biological carryover effects: linking common concepts and mechanisms in ecology and evolution, Ecosphere, 2014, 5, 1-11

[12] Wilcove, D.S., Wikelski, M.,Going, going, gone: is animal migration disappearing. PLoS biology, 2008, 6, e188.

[13] Gallinat A.S., Primack R.B., Wagner D.L., Autumn, the neglected season in climate change research, 2015, TREE, 30, 169-176

[14] Emanuel, K., Assessing the present and future probability of Hurricane Harvey's rainfall, 2017, Proceedings of the National Academy of Sciences, https://doi.org/10.1073/ pnas.1716222114

[15] Watson, K.M., Harwell, G.R., Wallace, D.S., Welborn, T.L., Stengel, V.G., McDowell, J.S., Characterization of peak streamflows and flood inundation of selected areas in southeastern Texas and southwestern Louisiana from the August and September 2017 flood resulting from Hurricane Harvey, 2018, U.S. Geological Survey Scientific Investigations Report 2018-5070, https://doi.org/10.3133/sir20185070.

[16] Oberhauser, K. S., Solensky, M. J. (Eds.), The monarch butterfly: biology \& conservation. Cornell university press, 2004

[17] Wiley, J.W., Wunderle, J.M., The effects of hurricanes on birds, with special reference to Caribbean islands. Bird Conservation International, 1993, 3, 319-349

[18] 18 Van Den Broeke, M. S. (2013). Polarimetric radar observations of biological scatterers in Hurricanes Irene (2011) and Sandy (2012). Journal of atmospheric and oceanic technology, 30(12), 2754-2767.

[19] Barrow Jr, W., Chadwick, P., Couvillion, B., Doyle, T., Faulkner, S., Jeske, C., et al., Cheniere forest as stopover habitat for migrant landbirds: immediate effects of Hurricane Rita In Farris, G. S., Smith, G. J., Crane, M. P., Demas, C. R., Robbins, L. L., \& Lavoie, D. L.. (Eds.) Science and the storms: The USGS response to the hurricanes of 2005 (No. 1306). US Geological Survey, 2005, pp147-156.

[20] Barrow Jr, W., Buler, J., Couvillion, B., Diehl, R., Faulkner, S., Moore, F., \& Randall, L. (2005). Broad-scale response of landbird migration to the immediate effects of Hurricane Katrina. In Farris, G. S., Smith, G. J., Crane, M. P., Demas, C. R., Robbins, L. L., \& Lavoie, D. L.. (Eds.) Science and the storms: The USGS response to the hurricanes of 2005 (No. 1306). US Geological Survey, 2005, pp131-136

[21] Wiedenfeld, D.A., Wiedenfeld, M.G., Large Kill of Neotropical Migrants by Tornado and Storm in Louisiana, April 1993 (Alta Mortandad de Migratorios Neotropicales Causado por un Tornado y Una Tormenta en Luisiana). Journal of Field Ornithology, 1995, 70-80

[22] Waide, R.B., Summary of the response of animal populations to hurricanes in the Caribbean. Biotropica, 1991, 23, 508-512

[23] Chapman, J.W., Reynolds, D.R., Wilson, K., Long-range seasonal migration in insects: mechanisms, evolutionary drivers and ecological consequences, 2015, Ecology letters, 18, 287-302

[24] May, M.L., A critical overview of progress in studies of migration of dragonflies (Odonata: Anisoptera), with emphasis on North America. Journal of Insect Conservation, 2013, 17, 1-15

[25] Popa-Lisseanu, A.G., Voigt, C.C., Bats on the move. Journal of Mammalogy, 2009, 90, 1283-1289

[26] Wiederholt, R., López-Hoffman, L., Cline, J., Medellín, R.A., Cryan, P., Russell, A., et al., Moving across the border: modeling migratory bat populations, 2013, Ecosphere, 4, 1-16

[27] Moskowitz, D., Moskowitz, J., Moskowitz, S., Moskowitz, H., Notes on a large dragonfly and butterfly migration in New Jersey. Northeastern Naturalist, 2001, 8, 483-490

[28] Clarke, A.R., Zalucki, M.P., Monarchs in Australia: on the winds of a storm?. Biological Invasions, 2004, 6, 123-127

[29] Freeman, B. (2003). A fallout of black witches (Ascalapha odorata) associated with Hurricane Claudette. News of the Lepidopterists' Society, 45(3), 71.

[30] Ries, L., Oberhauser, K.. A citizen army for science: quantifying the contributions of citizen scientists to our understanding of monarch butterfly biology, BioScience, 65, 419-430

[31] Kossin, J.P., Is the North Atlantic hurricane season getting longer?, 2008, Geophysical Research Letters, https://doi. org/10.1029/2008GL036012

[32] https://journeynorth.org/tm/monarch/FallHazards_ Hurricanelke.html

[33] Zipkin, E.F., Ries, L., Reeves, R., Regetz, J., Oberhauser, K. S., Tracking climate impacts on the migratory monarch butterfly. Global Change Biology, 2012, 18, 3039-3049

[34] Saunders, S.P., Ries, L., Oberhauser, K.S., Zipkin, E.F., Evaluating confidence in climate-based predictions of population change in a migratory species, 2016, Global ecology and biogeography, 25, 1000-1012

[35] Alonso-Mejía, A., Rendon-Salinas, E., Montesinos-Patiño, E., Brower, L.P., Use of lipid reserves by monarch butterflies overwintering in Mexico: implications for conservation. Ecological Applications, 1997, 7, 934-947

[36] Saunders, S.P, Ries, L., Neupane, N., Ramirez, M.I., GarciaSerranod, E., Zipkin, E.F., Are monarch butterflies declining because of mortality during the autumn migration?, In press, Proceedings of the National Academy of Sciences.

[37] 37. Satterfield, D.A., Marra, P.P., Sillett, T.S., Altizer, S., Responses of migratory species and their pathogens to supplemental feeding, 2018, Phil. Trans. R. Soc. B, 373, DOI: $10.1098 /$ rstb. 2017.0094

[38] Satterfield D. A., Maerz J. C., Altizer S., Loss of migratory behaviour increases infection risk for a butterfly host, 2015, Proc. R. Soc. B, 282, http://dx.doi.org/10.1098/ rspb.2014.1734

[39] Batalden R. V., Oberhauser, K. S., Potential changes in eastern North American monarch migration in response to an introduced milkweed, Asclepias curassavica, In: K. S. Oberhauser, K. R. Nail, S. M. Altizer [Eds.], Monarchs in a Changing World: Biology and Conservation of an Iconic Insect, Cornell University Press, Ithaca, NY, 2015 
[40] Baum K. A., Sharber W. V., Fire creates host plant patches for monarch butterflies, Biol Lett., 2012, 8, 968-7

[41] Baum K. A., Mueller, E., Grassland and roadside management practices affect milkweed abundance and opportunities for monarch recruitment, In: K. S. Oberhauser, K. R. Nail, S. M. Altizer [Eds.], Monarchs in a Changing World: Biology and Conservation of an Iconic Insect, Cornell University Press, Ithaca, NY, 2015

[42] Calvert W. H., Patterns in the spatial and temporal use of Texas milkweeds (Asclepiadaceae) by the monarch butterfly (Danaus plexippus L.) during fall, 1996, J Lepid Soc., 1999, 53, 37-44

[43] Prysby M. D., Oberhauser K. S., Temporal and geographic variation in monarch densities: Citizen scientists document monarch population patterns, In: K. S. Oberhauser, M. J. Solensky [Eds.], The Monarch Butterfly: Biology and Conservation, Cornell University Press, Ithaca, NY, 2004

[44] Flockhart D. T. T., Brower L. P., Ramirez M. I., Hobson K. A., Wassenaar L. I., Altizer S., Norris D. R., Regional climate on the breeding grounds predicts variation in the natal origin of monarch butterflies overwintering in Mexico over 38 years, Glob Change Biol., 2017, 23, 2565-2576
[45] Huffman, G.J., Adler, R.F., Bolvin, D.T., Nelkin, E.J., The TRMM Multi-satellite Precipitation Analysis (TMPA). In: F. Hossain and M. Gebremichael, [Eds.], Satellite Rainfall Applications for Surface Hydrology, Springer Verlag, 2010

[46] Policelli, F., Slayback, D., Brakenridge, B., Nigro, J., Hubbard, A., Zaitchik, B., et al., The NASA Global Flood Mapping System. In: Venkat Laksmi [Ed.] Remote Sensing of Hydrological Extremes, Springer International Publishing, 2017

[47] Eric, V., Justice, C., Csiszar, I., Eidenshink, J., Myneni, R, Baret, F., et al., NOAA Climate Data Record (CDR) of Normalized Difference Vegetation Index (NDVI), Version 4. NOAA National Centers for Environmental Information. doi:10.7289/V5PZ56R6, 2018

[48] Ries, L., Oberhauser, K. Taron, D., Rendon-Salinas, E., Connecting eastern monarch population dynamics across their migratory cycle. In: K. S. Oberhauser, K. R. Nail, S. M. Altizer [Eds.], Monarchs in a Changing World: Biology and Conservation of an Iconic Insect, Cornell University Press, Ithaca, NY, 2015

Supplemental Material: The online version of this article (DOI: 10.1515/ami-2018-0010) offers supplementary material. 